\title{
2019 Editor's Choice Award and Editor's Choice Articles
}

\author{
Kensuke Nakata ${ }^{1}$ \\ (C) Japan Ethological Society 2019
}

The editorial committee of the Journal of Ethology awards a prize for the best paper published in the journal, the Editor's Choice Award, every year. In addition, the committee selects certain outstanding papers as Editor's Choice articles. I am very pleased to announce the award winner and the list of the Editor's Choice articles for 2019.

\section{Editor's Choice Award}

Naoko Irie, Mariko Hiraiwa-Hasegawa, and Nobuyuki Kutsukake (2019) Unique numerical competence of Asian elephants on the relative numerosity judgment task (Volume 37, Issue 1, pp 111-115).

The authors demonstrate that Asian elephants' sense of numerosity differs from that of African elephants, and is similar to that of humans. The editorial committee considered the paper astonishing, since it reveals the diversity and convergence of numerical sense among different animals, using an ingenious study method. The committee also recognized the considerable social response to the paper.

\section{Editor's Choice Articles}

Ayami Sekizawa, Shin G. Goto, and Yasuhiro Nakashima (2019) A nudibranch removes rival sperm with a disposable spiny penis (Volume 37, Issue 1, pp 21-29).

Masaru Hasegawa and Nobuyuki Kutsukake (2019) Kin selection and reproductive value in social mammals (Volume 37, Issue 2, pp 139-150).

Grete E. Wilson-Henjum, Jacob R. Job, Megan F. McKenna, Graeme Shannon, and George Wittemyer (2019) Alarm call modification by prairie dogs in the presence of juveniles (Volume 37, Issue 2, pp 167-174).

Kensuke Nakata

nakatake@kyoto-wu.ac.jp

1 Kyoto Women's University, Kyoto, Japan
Jumpei Uematsu, Masayuki Hayashi, Hiroyuki Shimoji, Michel-Olivier Laurent Salazar, and Kazuki Tsuji (2019) Context-dependent aggression toward non-nestmates in the ant Diacamma sp. from Japan (Volume 37, Issue 3, pp 259-264).

Kohji Takahashi and Reiji Masuda (2019) Nurture is above nature: nursery experience determines habitat preference of red sea bream Pagrus major juveniles (Volume 37, Issue 3, pp 317-323).

\section{Open access}

These papers have now been made open access by the support from the Japan Ethological Society funded by JSPS KAKENHI Grant Number 18HP2005. I hope these papers will be read by many colleagues and will contribute to future studies of animal behavior.

\section{References}

Hasegawa M, Kutsukake N (2019) Kin selection and reproductive value in social mammals. J Ethol 37:139-150

Irie N, Hiraiwa-Hasegawa M, Kutsukake N (2019) Unique numerical competence of Asian elephants on the relative numerosity judgment task. J Ethol 37:111-115

Sekizawa A, Goto SG, Nakashima Y (2019) A nudibranch removes rival sperm with a disposable spiny penis. J Ethol 37:21-29

Takahashi K, Masuda R (2019) Nurture is above nature: nursery experience determines habitat preference of red sea bream Pagrus major juveniles. J Ethol 37:317-323

Uematsu J, Hayashi M, Shimoji H, Salazar MOL, Tsuji K (2019) Context-dependent aggression toward non-nestmates in the ant Diacamma sp. from Japan. J Ethol 37:259-264

Wilson-Henjum GE, Job JR, McKenna MF, Shannon G, Wittemyer G (2019) Alarm call modification by prairie dogs in the presence of juveniles. J Ethol 37:167-174

Publisher's Note Springer Nature remains neutral with regard to jurisdictional claims in published maps and institutional affiliations. 